\title{
The effectiveness of parent participation in occupational therapy for children with developmental delay
}

This article was published in the following Dove Press journal:

Neuropsychiatric Disease and Treatment

\author{
Chien-Lin $\operatorname{Lin}^{1,2}$ \\ Chin-Kai Lin ${ }^{3}$ \\ Jia-Jhen $\mathrm{Yu}^{4}$ \\ 'Department of Physical Medicine \\ and Rehabilitation, China Medical \\ University Hospital, ${ }^{2} \mathrm{School}$ of \\ Chinese Medicine, College of Chinese \\ Medicine, China Medical University, \\ ${ }^{3}$ Program of Early Intervention, \\ Department of Early Childhood \\ Education, National Taichung \\ University of Education, ${ }^{4}$ Occupation \\ Therapy Unit of Rehabilitation \\ Techniques Section, Lin Shin Medical \\ Corporation Wuri Lin Shin Hospital, \\ Taichung, Taiwan
}

Introduction: This study aims to explore the impact of Parent Participation Program on the development of developmental delay children.

Methods: Pretest-posttest equivalent-group experimental design study was used in this paper. A total of 30 pairs of developmental delay children aged 0-72 months and their parents participated into this study. They were divided into two groups, namely control group and experimental group, according to parents' wishes. The objects of study in control group received 16 courses of direct rehabilitation therapy; those in experimental group received 8 courses of direct rehabilitation therapy and 8 courses of instruction and tracking of Parent Participation Program. The duration of the intervention was 8 weeks. All cases should be evaluated before and after the intervention, to analyze the difference before and after intervention and among groups. The statistical methods in this paper included descriptive analysis, Chi-square test, independent sample $t$-test, pair-sample $t$-test.

Results and conclusion: The intervention of Parent Participation Occupational Program has positive impact on the development of developmental delay children in various fields. Among all the intervention results, the progress of the experimental group is 1.895 times more than that of the control group. With parent involvement, Parent Participation Occupational Therapy can promote the cognitive ability, language ability, action ability (gross and fine movement), social competence and self-care ability of children with developmental delay. Finally, the researcher presents suggestions and directions for future research in accordance with the results.

Keywords: early intervention, preschool, developmental delay

\section{Introduction}

Article 28 of Taiwan's Special Education Act in 2013 stipulates that schools below senior high school shall set out individual education plans (IEPs) for students with disabilities in team collaboration. Parents of these students shall be invited to participate in the IEP, and the related personnel shall be invited by parents to accompany them when necessary. The service spirit of early intervention in Taiwan in the past decade and Implementation Program of Early Intervention Services for Children with Developmental Delays designed in accordance with the Child and Juvenile Welfare Act, the Special Education Act, and the Law on the Protection of the Rights and Interests of Persons with Disabilities are all based on the family centered service concept.

The parent participation service model can be divided into parental involvement in school education ${ }^{1}$ and parental participation in medical interventions. ${ }^{2,3}$ The positive impact from studies included enhancing family cognition, parents' self-growth, ${ }^{4,5}$ parenting skills and treatment knowledge, ${ }^{6,7}$ promoting children's development and
Correspondence: Jia-Jhen $Y_{u}$ Occupation Therapy Unit of Rehabilitation Techniques Section, Lin Shin Medical Corporation Wuri Lin Shin Hospital, No 36, Section 3, Hui Zhong

Road, Nantun District, Taichung, Taiwan Tel +886422586688

Fax +886 422523580

Email kymcojr100@yahoo.com.tw
Neuropsychiatric Disease and Treatment 2018:14 623-630

623

Dovepress if in 0 (c) (i) (5) 2018 Lin et al. This work is published and licensed by Dove Medical Press Limited. The full terms of this license are available at https://www.dovepress.com/terms.php cc. ${ }_{\mathrm{BY}} \mathrm{NC}$ and incorporate the Creative Commons Attribution - Non Commercial (unported, v3.0) License (http://(creativecommons.org/licenses/by-n/3.00). By accessing the work you hereby accept the Terms. Non-commercial uses of the work are permitted without any further permission from Dove Medical Press Limited, provided the work is properly attributed. For permission for commercial use of this work, please see paragraphs 4.2 and 5 of our Terms (https://www.dovepress.com/terms.php). 
functional skills in various fields, ${ }^{6-8}$ improving the learning quality of children with developmental delay, improving parent-child interaction, and successfully establishing the partnership between parents and professionals. ${ }^{9}$ In these researches, children with developmental delay were in broad categories. The research plan and results covered wide areas, including adaptability and movement ability, ${ }^{2}$ generalization of self-care ability and learning willingness, ${ }^{2}$ and the individual learning of functional subjects ${ }^{1}$ for children with developmental delay. Moreover, this aids parents in their psychology, upbringing and information, and perceptions.

Extensive research has led to many positive outcomes, but the negative impacts show that parents are frequently beset by busy jobs, too many family affairs, personal discomforts, multiple roles, and related factors. It will change the duration and willingness of parents to participate in the early intervention, causing negative impacts on the children's development. ${ }^{10}$ There are still only a few experimental studies ${ }^{1-4,6,7}$ and few papers at Taiwan ${ }^{11}$ used to support the impact of parent participation on the growth of children with developmental delay. This article aims to study how to make children with developmental delay progress in many fields through parent participation as an occupational therapy in the medical setting at Taiwan.

This article mainly explores the effectiveness of parent participation in occupational therapy on the development of children with developmental delay. It is expected that the study can support the effectiveness of parent participation. Therefore, the purpose of this study is to explore the impact of parent participation in the occupational therapy on the cognition, language, gross motor, fine motor abilities, social competence, and self-care ability of children with developmental delay, in order to understand the effect of parental participation on occupational therapy.

\section{Participants and methods}

\section{Participants}

A total of 15 pairs of developmentally delayed or suspected children with developmental delay, aged 0-6 years, and their parents participated in this study. In pretest, the chronological ages of the children were 10-69 months, and the average age was $46.8 \pm 16.0$ months. The developmental ages were 5.3-61.2 months, and the average developmental age was $34.49 \pm 15.20$ months. There were 20 boys $(66.67 \%)$ and 10 girls (33.33\%) (Table 1). Participants met the following criteria of sample selection: 1) the chronological age was 0-6 years; 2) they were developmental delay or suspected developmental delay children, according to the evaluation of a physician and therapists; and 3) they were participants with parental consent and all involved parents signed a written informed consent. Exclusion criteria were as follows: 1) parents and children in the experimental group and control group were reluctant to participate in the whole process, $\sim 2$ months; 2) children diagnosed as traumatic brain injury and neurodegenerative diseases; 3) parents in two groups with no enthusiasm and alternative reasons as to why a parent did not want to participate (eg, time and schedule); and 4) children participating in other traditional Chinese medicine and preschool training courses were excluded, to avoid confusion in the findings. This study was approved by the Human Review Board, Taichung Veterans General Hospital in 2016 (IRB code: SF15299A).

Among the experimental children, there were nine boys $(60 \%)$ and six girls (40\%). Among children in the control group, there were 11 boys ( $73.33 \%$ ) and four girls (26.67\%) (Table 1$)$. There were no significant difference in the gender of children with developmental delay between the experimental group and the control group $\left(\chi^{2}=0.6, P=0.439\right)$ and also no significant difference in the delay degree between the two groups $\left(\chi^{2}=3.06\right.$, $P=0.165$ ), with homogeneity, as shown in Table 1 . There was no significant difference in the chronological age (experimental group 48.27 \pm 16.20 , control group 46.02 \pm 15.37 ) and developmental age (experimental group 30.22 \pm 12.49 , control group $38.27 \pm 17.01$ ) of developmentally delayed children between the two groups, as shown in Table 2. There was no significant difference in Comprehensive Developmental Inventory for Infants and Toddlers (CDIIT) pretest between two groups. It can be seen that two groups were equivalent in group design.

Table I Comparison of control variables between two groups, by categorical variable

\begin{tabular}{|c|c|c|c|c|c|c|c|}
\hline \multirow[t]{2}{*}{$\begin{array}{l}\text { Characteristics } \\
\text { of children }\end{array}$} & \multicolumn{2}{|l|}{$\begin{array}{l}\text { All cases } \\
(n=30)\end{array}$} & \multicolumn{2}{|c|}{$\begin{array}{l}\text { Experimental group } \\
(n=\mid 5)\end{array}$} & \multicolumn{2}{|c|}{$\begin{array}{l}\text { Control group } \\
(n=15)\end{array}$} & \multirow[t]{2}{*}{$\begin{array}{l}\text { Chi-square } \\
\text { value }\end{array}$} \\
\hline & Number & $\%$ & Number & $\%$ & Number & $\%$ & \\
\hline Gender & & & & & & & 0.60 \\
\hline Boy & 20 & 66.6 & 9 & 60 & 11 & 73.33 & \\
\hline Girl & 10 & 33.33 & 6 & 40 & 4 & 26.67 & \\
\hline Delay degree & & & & & & & 3.06 \\
\hline-1 to $-2 \mathrm{SD}$ & 13 & 43.34 & 4 & 26.67 & 9 & 60 & \\
\hline-2 to $-3 \mathrm{SD}$ & 10 & 33.33 & 6 & 40 & 4 & 26.67 & \\
\hline-3 SD above & 7 & 23.33 & 5 & 33.33 & 2 & 13.33 & \\
\hline
\end{tabular}


Table 2 Comparison of physiological age and developmental age between the two groups

\begin{tabular}{|c|c|c|c|c|c|c|c|}
\hline \multirow[t]{2}{*}{ Variables } & \multicolumn{2}{|c|}{$\begin{array}{l}\text { All cases } \\
(n=30)\end{array}$} & \multicolumn{2}{|c|}{$\begin{array}{l}\text { Experimental group } \\
(n=\mid 5)\end{array}$} & \multicolumn{2}{|c|}{$\begin{array}{l}\text { Control group } \\
(n=15)\end{array}$} & \multirow[t]{2}{*}{$t$ value } \\
\hline & Mean & SD & Mean & SD & Mean & SD & \\
\hline Physiological age & 46.8 & 16.0 & 48.27 & 16.20 & 46.02 & 15.37 & $0.38 I$ \\
\hline Developmental age & 34.25 & 15.22 & 30.22 & 12.49 & 38.27 & 17.01 & -1.475 \\
\hline
\end{tabular}

\section{Research design and experimental procedure}

This research adopted pretest-posttest equivalent-group experimental design of quasi-experimental design. The experimental procedure covered calling up participants of study, conducting pretests, grouping, engaging in occupational therapy, and conducting posttests. In accordance with the inclusion criteria of this study, the researcher explained the objective of study, procedure, task and possible burdens, and impacts of participation in the study to parents. Parents must agree to participate in the occupational therapy twice a week for 2 months. Consenting person signed the consent form for this study.

Pretest and posttest were conducted by an occupational therapist B with 2 years of work experience, who did not participate in the invention of the study. The occupational therapist B did not know the groups of participants or the details of the study. The occupational therapist $\mathrm{A}$ is the researcher with 8 years of early intervention experience who participated in the study implementation but did not participate in the research measurement.

In this article, there were two groups according to parents' willingness of participation. The children in the experimental group went to hospitals to receive two sessions of occupational therapy in 1 week; among which, one course was occupational therapy, whereas the other course was with parent participation. Parents must participate in the occupational therapy course. The researcher and parents together made the goal of the occupational therapy and shared life experience to establish a good relationship of trust. The children in the control group went to hospitals to receive two sessions of occupational therapy. The therapy for the two groups was 30 min per session, one-to-one treatment for 2 months. If a child was absent from the session of study, researchers negotiated with parents to find some extra time to make up a missed treatment session. For the experimental group, there were eight courses of occupational therapy and eight courses of parent participation in occupational therapy; for the control group, there were 16 courses of occupational therapy, totaling $240 \mathrm{~min}$. There was no chance to talk among the two groups. The treatment time was different, in order to avoid the threats to internal validity, such as comparison and sharing.
The treatment plan included 1) drawing up the objectives of the occupational therapy plan; 2) designing integrated rehabilitation activities according to different needs of parents and children, including the elements required to promote the improvement of children's cognition, language, action, social, and self-care abilities and induce functional activity in children (such as sitting/standing balance, hand reaching/grabbing ability, normalization of muscle tone, and sensory modulation ability), the activities associated with the emotional act or skill of a functional role (player), enhancing parental care skills, and encouraging parent-child interaction; rehabilitation activities would be performed in the therapeutic room, and parents could watch or act as collaborative therapy personnel; 3) executing details and method description, which included, according to the advantages of the primary caregivers, different types of materials help understand the detailed activity of the plan and consisted of the written materials, email for updating needs at any time, pictures, photos, tapes, DVDs, and so on; 4) filling out executive logging for parent participation in occupational therapy (parent's understanding of children's therapy plan, executive frequency, executive skill, one time per week).

\section{Outcome measures}

The CDIIT test $\mathrm{t}^{12}$ was used as a tool for sample selection in this article. The test consisted of five subtests, namely cognitive, verbal, motor, social, and self-care abilities. It is a set of tests suitable for general infants and young children or infants with developmental delays. Standardization is applied for the developmental assessment of children aged 3-71 months. This set of tests has two kinds of testing procedures, namely screening and diagnosis. A total of 3,703 infants and young children over Taiwan were regarded as the standard samples to establish age rate in overall development and all fields of development, $Z$ fraction of 18 age groups, percentile rank and development quotient, and other standard fraction norms. If the testing score is higher, the developmental age is the greater, with direct correlation with the chronological age. The testing results of screening testing passages are divided into suspended delay and normal. If the 
$Z$ value of any subtest or total score is less than -2 , the diagnosis is developmentally delay. If $Z$ is in the range of -1 and -2 , the diagnosis is suspended developmental delay. The retest reliability is in the range of $0.90-0.99$; the internal consistency is in the range of $0.75-0.99 .{ }^{13}$ The accuracy for determining typically developed children and seriously developmentally delayed children is higher, $\sim 82.1 \%$ and $84.6 \%$. The accuracy for determining mild developmentally delayed children is lower, $\sim 55 \%$.

\section{Data analysis}

SPSS 13.0 English version was used for data processing and analysis. The used statistical methods included descriptive analysis, Chi-square test, independent $t$-test, and pairedsample $t$-test. The significant level of all statistical methods is $P<0.05$.

\section{Results}

\section{The impact of parent participation in the occupational therapy}

The results of paired $t$-test showed that there was a significant difference in the mean of developmental raw score, including cognitive, verbal, gross motor, fine motor abilities, total score of motor, social, and self-care abilities, and total testing score between before and after the experimental intervention for the experimental group (Table 3). For the control group, there was a significant difference on the cognitive, verbal, gross motor, fine motor abilities, total score of motor, and total testing score.

In the control group, total testing score made the greatest progress, achieving an average improvement of 16.66 points, followed by total motor score, achieving an average improvement of 5.06. However, self-care ability made the smallest progress, achieving an average improvement of 0.86 points.

In the experimental group, total testing score made the greatest progress, achieving an average improvement of 66.33 points during 8 weeks ( 2 months) of the intervention period, followed by cognitive ability, achieving an average improvement of 17.26 points. Gross motor ability made the smallest progress, achieving an average improvement of 6.66. The progress of the experimental group was 49.67 points more in the total testing score than that of the control group.

Table 3 Comparison of mean of raw scores of development on differ stage between two groups

\begin{tabular}{|c|c|c|c|c|c|c|c|}
\hline \multirow[t]{2}{*}{ Variable groups } & \multicolumn{2}{|c|}{ Pretest (TI) } & \multicolumn{2}{|c|}{ Posttest (T2) } & \multicolumn{2}{|c|}{ Differences (T2 - TI) } & \multirow[t]{2}{*}{$t$ value } \\
\hline & Mean & SD & Mean & SD & Mean & SD & \\
\hline \multicolumn{8}{|l|}{ Cognitive ability } \\
\hline Experimental group & 44.40 & 19.56 & 61.66 & 18.85 & 17.26 & 12.65 & $-5.286 * * *$ \\
\hline Control group & 51.93 & 22.29 & 56.40 & 22.14 & 4.46 & $6.56 \mathrm{I}$ & $-2.617^{*}$ \\
\hline \multicolumn{8}{|l|}{ Verbal ability } \\
\hline Experimental group & 37.46 & 15.78 & 50.53 & 13.01 & 13.06 & 9.66 & $-5.238 * * *$ \\
\hline Control group & 42.46 & 16.43 & 47.20 & 16.57 & 4.73 & 3.28 & $-5.583 * * *$ \\
\hline \multicolumn{8}{|l|}{ Gross motor ability } \\
\hline Experimental group & 38.86 & 10.30 & 45.53 & 10.26 & 6.66 & 4.89 & $-5.276 * * *$ \\
\hline Control group & 43.33 & 8.12 & 45.13 & 8.23 & 1.80 & 2.31 & $-3.024 * *$ \\
\hline \multicolumn{8}{|l|}{ Fine motor ability } \\
\hline Experimental group & 25.33 & 8.62 & 33.53 & 7.79 & 8.20 & 7.05 & $-4.503 * * *$ \\
\hline Control group & 27.60 & 8.64 & 30.86 & 8.46 & 3.26 & 2.63 & $-4.808 * * *$ \\
\hline \multicolumn{8}{|l|}{ Total motor score } \\
\hline Experimental group & 64.20 & 18.66 & 79.06 & 17.69 & 14.86 & 11.56 & $-4.980 * * *$ \\
\hline Control group & 70.93 & 16.52 & 76.00 & 16.68 & 5.06 & 3.88 & $-5.055 * * *$ \\
\hline \multicolumn{8}{|l|}{ Social ability } \\
\hline Experimental group & 33.06 & 9.18 & 43.86 & 9.26 & 10.8 & 8.19 & $-5.104 * * *$ \\
\hline Control group & 39.86 & 10.76 & 41.40 & 11.63 & 1.53 & 5.40 & -1.098 \\
\hline \multicolumn{8}{|l|}{ Self-care ability } \\
\hline Experimental group & 27.60 & 8.91 & 36.20 & 9.51 & 8.6 & 6.31 & $-5.278 * * *$ \\
\hline Control group & 33.53 & 9.92 & 34.40 & 10.20 & 0.86 & 3.73 & -0.898 \\
\hline \multicolumn{8}{|l|}{ Total testing score } \\
\hline Experimental group & 206.06 & 66.28 & 272.40 & 62.97 & 66.33 & 34.50 & $-7.445 * * *$ \\
\hline Control group & 238.73 & 71.97 & 255.40 & 74.11 & 16.66 & 15.12 & $-4.269 * * *$ \\
\hline
\end{tabular}

Notes: $* P<0.05 . * * P<0.01$. $* * * P<0.001$. 


\section{Differences in developmental age in CDIIT before and after experiment intervention}

There was a significant difference in developmental age between before and after the experimental group intervention (Table 4), including cognitive, verbal, gross motor, fine motor abilities, total score of motor, social, and self-care abilities, and total testing score $(P<0.05)$. For the control group, the developmental age reached the statistically significant difference in cognitive, verbal, gross motor, fine motor abilities, and total testing score $(P<0.05)$, but it failed to reach the significant difference in total motor score, social, and selfcare abilities.

In the control group, the verbal ability made the greatest progress, achieving an average improvement of 6.54 months, followed by fine motor, achieving an average improvement of 6.04 months. However, self-care ability made the smallest progress, achieving an average improvement of 1.65 months.

In the experimental group, the total testing score made the greatest progress, achieving an average improvement of
17.86 months during the 8 weeks ( 2 months) of intervention, followed by total motor score, achieving an average improvement of $\mathbf{1 7 . 1 6}$ months. However, self-care ability made the smallest progress, achieving an average improvement of 13.72 months. The progress of the experimental group was 13.82 months more than that of the control group and also more than that of general child development ( 2 months) in the norm.

The effects on total testing score and gross motor ability were the largest, namely 2.81 and 2.12 ; those of social and verbal abilities were the lowest, namely 1.50 and 1.49 ; the mean effect rate of developmental age in all fields was 1.90 , which was the greatest impact size. In other words, after experimental intervention, for the developmental progress in all fields, the progress of the experimental group was 1.90 times the SD of the progress of the control group (the mean score of experimental group was higher than the scores of $90 \%$ of the control group). The difference in the progress of total testing score and gross motor ability between the two groups was greater, and the difference in the progress of social ability and verbal ability between two groups was smaller.

Table 4 Comparison of pretest and posttest of developmental age of CDIIT between two groups

\begin{tabular}{|c|c|c|c|c|c|c|c|}
\hline \multirow[t]{2}{*}{ Variable groups } & \multicolumn{2}{|c|}{ Pretest (TI) } & \multicolumn{2}{|c|}{ Posttest (T2) } & \multicolumn{2}{|c|}{ Difference (T2 - TI) } & \multirow[t]{2}{*}{$t$ test } \\
\hline & Mean & SD & Mean & SD & Mean & SD & \\
\hline \multicolumn{3}{|l|}{ Cognitive ability } & & & \multicolumn{2}{|c|}{ Effect size: I.99 } & \\
\hline Experimental group & 36.02 & 16.64 & 52.40 & 16.64 & 14.38 & 10.76 & $-5.174 * * *$ \\
\hline Control group & 42.74 & 18.56 & 46.30 & 18.30 & 3.55 & 5.45 & $-2.524^{*}$ \\
\hline \multicolumn{5}{|l|}{ Verbal ability } & \multicolumn{2}{|c|}{ Effect size: 1.49} & \\
\hline Experimental group & 31.69 & 14.32 & 46.81 & 14.55 & 15.12 & 9.03 & $-6.482 * * *$ \\
\hline Control group & 38.67 & 16.82 & 45.22 & 18.96 & 6.54 & 5.74 & $-4.416 * * *$ \\
\hline \multicolumn{3}{|l|}{ Gross motor ability } & & & \multicolumn{2}{|c|}{ Effect size: 2.12} & \\
\hline Experimental group & 30.70 & 13.36 & 44.01 & 15.09 & $|3.3|$ & 10.46 & $-4.929 * * *$ \\
\hline Control group & 38.02 & 16.20 & 41.48 & 17.24 & 3.46 & 4.56 & $-2.933 *$ \\
\hline \multicolumn{3}{|l|}{ Fine motor ability } & & & \multicolumn{2}{|c|}{ Effect size: I.82 } & \\
\hline Experimental group & 30.70 & 14.40 & 47.70 & 16.46 & 17.00 & 15.67 & $-4.200 * * *$ \\
\hline Control group & 35.16 & 17.42 & 41.80 & 18.69 & 6.63 & 5.70 & $-4.503^{* * *}$ \\
\hline \multicolumn{3}{|l|}{ Total motor score } & & & \multicolumn{2}{|c|}{ Effect size: 1.55} & \\
\hline Experimental group & 29.31 & 14.70 & 45.75 & 15.79 & 16.44 & 10.97 & $-5.801 * * *$ \\
\hline Control group & 36.63 & 16.99 & 40.32 & 20.44 & 3.68 & 8.23 & -1.736 \\
\hline \multicolumn{3}{|l|}{ Social ability } & & & \multicolumn{2}{|c|}{ Effect size: 1.50} & \\
\hline Experimental group & 27.34 & 12.56 & 42.72 & 13.38 & 15.38 & 11.70 & $-5.082 * * *$ \\
\hline Control group & 37.58 & 15.20 & 40.14 & 17.35 & 2.56 & 8.54 & -1.164 \\
\hline \multicolumn{3}{|l|}{ Self-care ability } & & & \multicolumn{2}{|c|}{ Effect size: I.89 } & \\
\hline Experimental group & 27.70 & 10.19 & 41.42 & 14.60 & 13.72 & 9.12 & $-5.825 * * *$ \\
\hline Control group & 37.98 & 14.54 & 39.63 & 15.66 & 1.65 & 6.40 & -1.000 \\
\hline \multicolumn{3}{|l|}{ Total testing score } & & & \multicolumn{2}{|c|}{ Effect size: $2.8 \mathrm{I}$} & \\
\hline Experimental group & 30.22 & 12.49 & 46.75 & 14.79 & 16.52 & 7.34 & $-8.719 * * *$ \\
\hline Control group & 38.76 & 16.83 & 43.05 & 18.80 & 4.29 & 4.36 & $-3.559 * *$ \\
\hline
\end{tabular}

Notes: $* P<0.05$. $* * P<0.01$. $* * * P<0.001$.

Abbreviation: CDIIT, Comprehensive Developmental Inventory for Infants and Toddlers. 


\section{Differences in developmental progression between two groups}

After 8 weeks of parent participation in the occupational therapy, an independent $t$-test was used to make a comparison of the progress between two groups to confirm the effectiveness of parent participation. The comparative analysis result of pretest and posttest treatments is shown in Table 5 .

The analysis result shows that, during 8 weeks ( 2 months) of experimental intervention, the development progress before and after the intervention of two groups had a statistically significant difference. The overall developmental age of the experimental group made an improvement of 17.82 months, and that of the control group made an improvement of 4 months. It indicates that the progress of developmental age in the experimental group is more than that in the control group and also more than that of children in general. For the effect size of experimental intervention, total testing score and gross motor ability had the highest effect. Social ability and verbal ability had a large effect but relatively lower than other fields. The average effect size on the developmental age in all fields was $>1.895$. The comparative analysis on the differences in the progress between two

Table 5 Comparison of differences in developmental progression between two groups

\begin{tabular}{|c|c|c|c|c|}
\hline Variable groups & Mean & SD & $t$ value & $P$-value \\
\hline Cognitive ability & & & $3.475^{* *}$ & 0.002 \\
\hline Experimental group & 14.38 & 10.76 & & \\
\hline Control group & 3.53 & 5.45 & & \\
\hline Verbal ability & & & $3.102 * *$ & 0.004 \\
\hline Experimental group & 15.12 & 9.03 & & \\
\hline Control group & 6.54 & 5.74 & & \\
\hline Gross motor ability & & & $3.343^{* *}$ & 0.002 \\
\hline Experimental group & $|3.3|$ & 10.46 & & \\
\hline Control group & 3.46 & 4.56 & & \\
\hline Fine motor ability & & & $2.407^{*}$ & 0.023 \\
\hline Experimental group & 17.00 & 15.67 & & \\
\hline Control group & 6.63 & 5.70 & & \\
\hline Total motor score & & & $3.724 * *$ & 0.001 \\
\hline Experimental group & 17.16 & 12.21 & & \\
\hline Control group & 3.01 & 8.19 & & \\
\hline Social ability & & & $3.602^{* *}$ & 0.001 \\
\hline Experimental group & 16.44 & 10.97 & & \\
\hline Control group & 3.68 & 8.22 & & \\
\hline Self-care ability & & & $4.194 * * *$ & 0.000 \\
\hline Experimental group & 13.72 & 9.12 & & \\
\hline Control group & 1.65 & 6.40 & & \\
\hline Total motor score & & & $5.106 * * *$ & 0.000 \\
\hline Experimental group & 66.33 & 34.50 & & \\
\hline Control group & 16.52 & 4.36 & & \\
\hline
\end{tabular}

Notes: $* P<0.05$. ${ }^{* * P}<0.0$ I. $* * * P<0.001$. groups by independent $t$-test shows that, after experimental intervention, for cognitive, verbal, gross motor, fine motor, social, self-care abilities, and total testing score of CDIIT, the children in experimental group made more progress than those in the control group. Therefore, it can be inferred that the intervention of parent participation in the occupational therapy has a significant impact on the development of children with developmental delay.

\section{Discussion}

\section{The impact of parent participation in the occupational therapy}

Both groups are highly homogeneous in cognitive, verbal, motor, social, and self-care abilities of pretest. Comparing results, differences before and after experimental group intervention in cognitive, verbal, gross motor, fine motor abilities, total motor score, social, self-care abilities, and total testing score are statistically significant. Wang ${ }^{4}$ raised the point that the closer the intervention approach to real life, the greater the normalization of the daily life functions of the children, and parents' psychological, nurturing, and information show more positive effects. However, this study result is generally the same as the findings of Tang et al, ${ }^{11}$ that is, the intervention of home activities (medical environment + home environment) can significantly affect development in various fields, but this article only discusses parent participation in occupational therapy (medical environment). There is a significant development in various fields. This is not exactly the same as in other studies.

Through sensory processing based on sensory integration theory for treating fecal incontinence in training children, Bellefeuille et a ${ }^{15}$ designed a daily defecation plan for parents following to significantly improve toilet behavior in children. Through parental involvement, Case-Smith and Nastro ${ }^{2}$ showed parents' feelings to have a positive effect. Furthermore, daily performance and fine movements in children were improved. In the research made by Chiarello et al, ${ }^{16}$ parents were asked to participate in daily routines of children (daily activities, productivity, leisure) at hospitals, and the research showed that children's daily performance and gross motor ability were improved.

Darch et $\mathrm{al}^{1}$ allowed teachers to effectively target the children's problem in the school through the method of parent participation (eg, when parents of those children with disruptive behavior had different ways of upbringing, teachers invited parents to participate in the routines in the school; through telephone calls or interviews, parents were allowed 
to engage in the plan of school, and parents shared their performance and skills to reduce disruptive behavior of children and improve the understanding of the school regulations/ practices) and more actively participate and improve the learning situations of children at each stage. Dunn et $\mathrm{al}^{17}$ used occupational therapy intervention involving authentic activity settings, family's daily routines, and sensory processing to coach 20 parents enhance the child participation and parent competence. The result shows that, if parents have a sense of competence, they can more significantly improve children' daily life functions. Holloway ${ }^{3}$ cooperated with parents through occupational therapists to improve upbringing skill and motor ability, swallowing function, touch, and hearing. Liu et $\mathrm{al}^{18}$ utilized parent participation, and pretest and posttest scores of the Bruininks-Oseretsky Test of Motor Proficiency were significantly improved during the intervention. In a parent questionnaire survey, the satisfaction with the overall movement of children was $>4$ points. Mai et $\mathrm{al}^{19}$ regarded children with cerebral palsy and their parents as the objects of intervention. The therapist designed and instructed six items of training and stipulated the performing times. Children performed in the treatment room, with parent assistance and collaborative treatment personnel. The research showed that there is a significant progress in the right knee extensor strength, standing on one right leg and agility these three dimensions. In terms of social validity of our study, the parents' rating scores (Likert 5-point scale) of progress for their children and parenting skills have significantly positive correlation with cognitive $(0.90)$, gross motor (0.68), fine motor abilities (0.67), total developmental score (0.83), and developmental age (0.77). Parents spend more time for the cases with greater progress in verbal, gross motor, fine motor abilities, total motor score, social ability, total developmental score, and developmental age. These positive correlations reached statistical significance except cognitive and self-care abilities.

Generally speaking, the intervention has significantly positive effects for parents and children with developmental delay.

\section{Conclusion}

Based on the study results and discussion, the following conclusions are summarized: 1) for subtests of the experimental group in five fields of CDIIT, pretest and posttest scores are significantly different. For subtests of the control group in five fields of CDIIT, pretest and posttest scores are significantly different in cognitive, verbal, gross motor, fine motor abilities, and total testing score. From the mean of overall developmental age corresponding to total testing score, the experimental group achieved an improvement of 17.86 months and the control group achieved an improvement of 4 months. The experimental group made more progress of 13.82 months than the control group and more progress than normally developed children in general. The results show that the experimental group, which accepted parent participation in the occupational therapy, made more progress in cognitive, verbal, gross motor, fine motor, social, and self-care abilities than the control group, which did not accept the parent participation course. Therefore, family participation in occupational therapy course can promote the development of children in five fields; and 2) the comparative analysis of pretest and posttest progress differences of CDIIT between the two groups shows that the size of the effect on developmental age in all fields is $>1.90$, which is significant.

\section{Suggestions}

Therapists are often affected by treatment hours in the current medical environment. One course of occupational therapy takes $30 \mathrm{~min}$, one after another. This may leave only $1 \mathrm{~min}$ for talking about individual rehabilitation plans with parents. Moreover, the issues involved in parent participation plan are more complex. It is virtually impossible to provide professional knowledge and skills for the needs of children and families in just $1 \mathrm{~min}$. However, the study results of parental direct participation in occupational therapy sessions shows that under direct supervision in a medical environment, the opportunity for parent participation has a positive impact on cognitive, verbal, gross motor, fine motor, social, and self-care abilities for children with developmental delay. Therefore, it is suggested that the professional staff push for early intervention in the medical environment to allow parents to participate in the therapy courses, while exchanging information and discussions while providing direct rehabilitation. This will also uncover a rehabilitation plan suitable for children and families in accordance with their individual needs. So, the intervention of parent participation in an occupational therapy plan not only can make children with developmental delay develop in all developmental fields but also can establish a good communication bridge and a better cooperation between parents and occupational therapists, which will improve parents' knowledge and skills in physiology, parenting, and information to support self-decision-making.

There has been no follow-up study after intervention. We wonder whether the developmental abilities of children with 
developmental delays can continue to improve. Therefore, a follow-up study is suggested after intervention to understand the continued effectiveness of a continued parents' therapy plan on children with developmental delay.

In this study, the sample size was small. A total of 30 people were participated, with 15 people for each group. The delay degree between control group and experimental group was not significantly different, but $P=0.165$ means that there was still some difference. The samples used in this article were limited to the result acquired by using this study design and sampling method. Therefore, the result could not be extrapolated to other diagnoses and children matching the criteria of exclusion. Based on the principles of being family centered, this article respects the family's choice of rehabilitation services. So, the intervention is determined by parents' choice. Therefore, it is impossible to exclude the impact of free will of parents in experimental group to participate in the intervention plan on the intervention result.

\section{Acknowledgments}

The authors would like to thank Ministry of Science and Technology in Taiwan (grant no 106-2410-H-142-006-SS2) for supporting the editing service of manuscript. No commercial party having a direct financial interest in the results of the research supporting this article has or will confer a benefit upon the authors or upon any organization with which the authors are associated.

\section{Disclosure}

The authors report no conflicts of interest in this work.

\section{References}

1. Darch C, Miao Y, Shippen P. A model for involving parents of children with learning and behavior problems in the schools. Prev Sch Fail. 2004;48(3): 24-34.

2. Case-Smith J, Nastro MA. The effect of occupational therapy intervention on mothers of children with cerebral palsy. Am J Occup Ther. 1993;47(9): 811-817.
3. Holloway E. Parent and occupational therapist collaboration in the neonatal intensive care unit. Am J Occup Ther. 1994;48(6):535-538.

4. May-Benson TA. Best practice occupational therapy for children and families in community settings. Occup Ther Health Care. 2012;26(4): 318-320.

5. Tomchek SD, Koenig KP. Occupational Therapy Practice Guidelines for Individuals with Autism Spectrum Disorder. Bethesda, MD: AOTA Press; 2016

6. Ros R, Graziano PA, Hart KC. Parental homework completion and treatment knowledge during group parent-child interaction therapy. J Early Intervention. 2017;14:299-320.

7. Marshall J, Adelman A, Kesten SM, Natale RA, Elbaum B. Parents' experiences navigating intervention systems for young children with mild language delays. J Early Intervention. 2017;10:180-198.

8. Hanft BE, Rush DD, Shelden MLL. Coaching Families and Colleagues in Early Childhood. 2nd Edition. Baltimore, MD: Paul H. Brookes; 2004.

9. Rush D, Shelden M. Evidence-based definition of coaching practices. CASEinPoint. 2005;1(6):1-6.

10. Dunn W. Best Practice Occupational Therapy for Children and Families in Community Settings. Thorofare: Slack Thorofare; 2011.

11. Tang MH, Lin CK, Lin WH, Chen CH, Tsai SW, Chang YY. The effect of adding a home program to weekly institutional-based therapy for children with undefined developmental delay: a pilot randomized clinical trial. J Chin Med Assoc. 2011;74(6):259-266.

12. Liao H-F, Pan Y-L. Test-retest and inter-rater reliability for the comprehensive developmental inventory for infants and toddlers diagnostic and screening tests. Early Hum Dev. 2005;81(11):927-937.

13. Liao H-F, Yao G, Wang T-M. Concurrent validity in Taiwan of the comprehensive developmental inventory for infants and toddlers who were full-term infants. Percept Mot Skills. 2008;107(1):29-44.

14. Wang T-M. Effectiveness of a parent support program for families with developmentally delayed children aged 0 to 3 years. Bull Spec Educ. 2013; 38(2):1-28.

15. Bellefeuille IB, Schaaf RC, Polo ER. Occupational therapy based on Ayres Sensory Integration in the treatment of retentive fecal incontinence in a 3-year-old boy. Am J Occup Ther. 2013;67(5):601-606.

16. Chiarello LA, Palisano RJ, Maggs JM, et al. Family priorities for activity and participation of children and youth with cerebral palsy. Phys Ther. 2016;90(9):1254-1264.

17. Dunn W, Cox J, Foster L, Mische-Lawson L, Tanquary J. Impact of a contextual intervention on child participation and parent competence among children with autism spectrum disorders: a pretest-posttest repeated-measures design. Am J Occup Ther. 2012;66(5):520-528.

18. Liu W-Y, Chen Y-J, Peng M-Y, Hwang W-B, Lin Y-H, Lien H-Y. Effects of developmental dance training on the degree of scouring of children with barriers to development: feasibility report. Physiotherapy. 2010;35(1):51-59.

19. Mai C-Y, Wu L, Wu W-G, et al. Effectiveness analysis of parents participating in rehabilitation model of children with cerebral palsy. Chin J Rehabil. 2007;22(1):60-62.
Neuropsychiatric Disease and Treatment

\section{Publish your work in this journal}

Neuropsychiatric Disease and Treatment is an international, peerreviewed journal of clinical therapeutics and pharmacology focusing on concise rapid reporting of clinical or pre-clinical studies on a range of neuropsychiatric and neurological disorders. This journal is indexed on PubMed Central, the 'PsycINFO' database and CAS,

\section{Dovepress}

and is the official journal of The International Neuropsychiatric Association (INA). The manuscript management system is completely online and includes a very quick and fair peer-review system, which is all easy to use. Visit http://www.dovepress.com/testimonials.php to read real quotes from published authors. 